Pacific Journal of Mathematic 


\section{ON BANACH SPACES HAVING A RADON-NIKODYM DUAL}

\section{Debieve}

The purpose of this paper is to prove a new characterisation of Banach spaces having a Radon-Nikodym dual, namely that if $E$ is a Banach space, then $E^{\prime}$ has the Radon-Nikodym property if and only if there exists an equivalent norm on $E$ such that for each $E$-valued measure $m$ of bounded variation, there exists an $E^{\prime}$-valued function $f$ with norm $1|m|$-a.e. such that $|m|=$ f.m.

1. Introduction. In [1], we have proved that if $E$ is a Banach space, $m$ an $E$-valued measure defined on a $\sigma$-algebra $\mathscr{A}$ of subsets of a set $T$, with bounded variation $|m|$, and if $\varepsilon$ is any positive number, then there exists an $E^{\prime}$-valued strongly measurable function $f$ defined on the set $T$, such that $\|f\|<1+\varepsilon$ and $|m|(A)=\int_{A} f d m$ for each $A$ in $\mathscr{A}$.

A very natural question which arises is the following: Does there always exist an $E^{\prime}$-valued strongly measurable function with norm 1 such that $|m|(A)=\int_{A} f d m$ for each $A$ in $\mathscr{A}$ ? Following the example given in [1], this seems to be possible.

Finally, an answer to that question was provided by F. Delbaen who proved the following unpublished theorem: If $E$ is a Banach space, the following are equivalent:

(a) $E^{\prime}$ has the Radon-Nikodym property

(b) For each equivalent norm on $E$, for each $E$-valued measure $m$ of bounded variation defined on a $\sigma$-algebra $\mathscr{A}$ of subsets of a set $T$, there exists a $|m|$-strongly measurable function $f$ from $T$ to $E^{\prime}$ such that $\|f\|=1$ $|m|$-a.e. and $|m|(A)=\int_{A} f d m$ for each $A$ in $\mathscr{A}$.

The purpose of this paper is to provide a positive answer to the following question: Is it possible to weaken assertion (b) by requiring the existence of an equivalent norm on the space having the property instead of assuming it for each equivalent norm on $E$.

2. Proof of the theorem. Before proving our theorem let us recall the Mazur density theorem and prove two lemmas. 
TheOREM (Mazur density theorem [5] p. 171). If $E$ is a separable Banach space, then for each equivalent norm on $E$, the set of smooth points of the unit sphere of $E$ is dense in the unit sphere.

LEMMA 1. Let $E$ be a Banach space such that $E^{\prime}$ is not separable, $B$ a dense subset of $S(E)=\{x \mid x \in E,\|x\|=1\}$ and $\varepsilon>0$. If we denote by $\Omega$ the first uncountable ordinal and by $S$ the set $\{i \mid i<\Omega\}$, then for each $i$ in $S$, there exists $x_{i}$ in $B$ and $x_{i}^{\prime}$ in $S\left(E^{\prime}\right)$, the unit sphere of $E^{\prime}$ such that $x_{i}^{\prime}\left(x_{i}\right)=1$ and $\left\|x_{i}^{\prime}-x_{j}^{\prime}\right\|>1-\varepsilon$ if $i \neq j$.

Proof. Let $i$ in $S$ and suppose that the families $\left(x_{j}\right)$ and $\left(x_{j}^{\prime}\right)$ are chosen for $j<i$.

As $E^{\prime}$ is not separable, $\bigcap_{j<i} \operatorname{Ker} x_{j}^{\prime} \neq\{0\}$.

Let $x \in S(E) \cap \bigcap_{j<i} \operatorname{Ker} x_{j}^{\prime}$ and choose $x_{i}$ in $B$ such that $\left\|x-x_{i}\right\|<\varepsilon$.

Now, if we choose $x_{i}^{\prime}$ in $S\left(E^{\prime}\right)$ such that $x_{i}^{\prime}\left(x_{i}\right)=1$ it is easy to see that we are done. $1-\varepsilon$.

$\left\|x_{i}^{\prime}-x_{j}^{\prime}\right\|>1-\varepsilon$ follows from the fact that if $j<i,\left(x_{i}^{\prime}-x_{j}^{\prime}\right)\left(x_{i}\right)>$

LeMma 2. For the same set $S$ as in Lemma 2, there exists a positive scalar measure $\mu$ on the $\sigma$-algebra $\mathscr{P}(S)$ of the subsets of $S$ such that $\mu(S)=1$ and $\mu(A)=0$ if $A$ is countable.

Proof. Let $i$ in $S$ and define $\mu_{i}$ as the evaluation measure at the point $i$. As the set of measures on the $\sigma$-algebra of the subsets of $S$ is the dual of the space of continuous bounded functions on $S$ for a locally convex topology, the family of measures has a cluster point which is a measure satisfying our requirement.

We are now ready for the proof of the following

THEOREM. For any Banach space E, the following are equivalent:

(1) $E^{\prime}$ has the Radon-Nikodym property.

(2) For each equivalent norm on $E$, for each E-valued measure $m$ of bounded variation defined on a $\sigma$-algebra $\mathscr{A}$ of subsets of a set $T$, there exists a function $f$ from $T$ into $E^{\prime}|m|$-strongly measurable such that $\|f(t)\|=1$ $|m|$-a.e. and $|m|(A)=\int_{A} f d m$ for each $A$ in $\mathscr{A}$.

(3) There exists an equivalent norm on $E$ such that for each $E$-valued measure $m$ of bounded variation defined on a $\sigma$-algebra $\mathscr{A}$ of subsets of a set $T$, there exists a function $f$ from $T$ into $E^{\prime}|m|$-strongly measurable such that $\|f(t)\|=1|m|$-a.e. and $|m|(A)=\int_{A} f d m$ for each $A$ in $\mathscr{A}$. 
Proof. (1) $\Rightarrow$ (2) It follows from the theorem we proved in [1] that for each integer $n$, there exists a function $f_{n}$ from $T$ into $E^{\prime}$ such that $f_{n}$ is $|m|$-strongly measurable, $1 \leq\left\|f_{n}(t)\right\|<1+1 / n$ and $|m|(A)=\int_{A} f_{n} d m$ for each $A$ in $\mathscr{A}$.

Let $G$ be the Banach subspace of $E^{\prime}$ generated by $\bigcup_{n=1}^{\infty} f_{n}(T)$.

As $G$ is separable and $E^{\prime}$ has Radon-Nikodym property, there exists a Banach space $F$ such that $F^{\prime}$ is separable and $G \subseteq F^{\prime}([3])$. Let $f$ be a pointwise $\sigma\left(F^{\prime}, F\right)$-cluster point of the sequence $\left(f_{n}\right) . f$ is $G$-valued, thus $E^{\prime}$-valued.

It is clear that $\|f\| \leq 1$ and that $f$ is $\sigma\left(F^{\prime}, F\right)$-measurable. As $|m|(A)$ $=\int_{A} f d m$ for each $A$ in $\mathscr{A}$, if we prove that $f$ is strongly measurable, the norm of $f$ will be greater than 1 and our assertion will be proved.

Let $m_{0}$ from $\mathscr{A}$ into $F^{\prime}$ defined by $m_{0}(A)(y)=\int_{A}\langle f, y\rangle d|m|$.

It is clear that $m_{0}$ is a measure with finite variation and that $\left|m_{0}\right|=|m|$.

As $F$ has the Radon-Nikodym property, there exists a measurable function $g$ from $T$ into $F^{\prime}$ such that $m_{0}(A)=\int_{A} g d|m|$ for each $A$ in $\mathscr{A}$.

It follows that if $y \in F, m_{0}(A)(y)=\int_{A}\langle g, y\rangle d|m|$ which shows that $\langle g, y\rangle=\langle f, y\rangle,|m|$-a.e. for each $y$ in $F$.

As $F$ is separable, it follows that $f=g|m|$-a.e. and that $f$ is strongly measurable which proves the first assertion.

As $(2) \Rightarrow(3)$ is obvious, it remains to show that

(3) $\Rightarrow$ (1) It is easy to prove that if property (3) is satisfied for $E$ it is also satisfied for each Banach subspace of $E$. Now as we have to prove that each separable subspace of $E$ has a separable dual, we only have to prove that if a separable Banach space satisfies (3), it has a separable dual.

Let us suppose that there exists a separable Banach space $E$ satisfying property (3) and such that $E^{\prime}$ is not separable. Let $B$ be the set of smooth points of the unit sphere $S(E)$ of $E$ which is dense in $S(E)$ by Mazur density theorem, $\varepsilon=1 / 4$ and apply Lemma 1 .

We define the function $f$ from $S$ to $E$ by $f(i)=x_{i}$. If $\mathscr{A}$ is defined as the set of inverse images by $f$ of the open subsets of $S(E)$, the function $f$ is strongly measurable. Let us choose on $\mathscr{A}$ a positive scalar measure $\mu$ such that $\mu(S)=1$ and $\mu(A)=0$ if $A$ is countable. Such a $\mu$ exists by Lemma 2. Now we define $m$ from $\mathscr{A}$ to $E$ by $m(A)=\int_{A} f d \mu$.

$m$ is clearly a measure of bounded variation and $|m|=\mu$. So there exists a function $g$ from $S$ into $E^{\prime}$ which is $\mu$-strongly measurable, $\|g\|=1$ $\mu$-a.e. and $\mu(A)=\int_{A} g d m$ for each $A$ in $\mathscr{A}$.

It follows that $\mu(A)=\int_{A}\langle f, g\rangle d \mu$ for each $A$ in $\mathscr{A}$ and that $\langle f, g\rangle=1$ $\mu$-a.e. 
So there exists a $\mu$-negligible subset $N$ of $S$ such that $g(i)(f(i))=1$ if $i \notin N$ and $g(S \backslash N)$ is separable If $i \notin N, g(i)(f(i))=g(i)\left(x_{i}\right)=1$.

As $x_{i}$ is a smooth point and $\|g(i)\|=1, g(i)=x_{i}$,

It follows that $\|g(i)-g(j)\| \geq 1-\varepsilon=3 / 4$ for $i \neq j$ in $S \backslash N$ which shows that $g(S \backslash N)$ is discrete.

As it is separable, it has to be countable. So $S \backslash N$ has to be countable which is impossible.

Acknowledgment. The author would like to express his deep gratitude to Professor D. H. Tucker for many helpful conversastions during the preparation of this paper while the author was in the mathematical department of the University of Utah, Salt Lake City, U.S.A.

\section{REFERENCES}

[1] C. Debieve, On a Radon-Nikodym problem for vector-valued measures, Pacific J. Math. 2, 107 (1983), 335-339.

[2] F. Delbaen, Private communicationo.

[3] J. Diestel and J. J. Uhl, Vector measures, Amer. Math. Soc. Mathematical Surveys no. 15.

[4] N. Dinculeanu, Vector Measures, Pergamon Press, New York.

[5] Holmes, Geometrical Functional Analysis and its Applications, Graduate Texts in Mathematics no. 24, Springer-Verlag.

Received March 10, 1984.

INSTITUT DE MATHEMATIQUES

PuRES ET APPLIQUEES

2, Chemin DU CyCLOTRon

B 1348 LouVAIN-LA-NeUVE

BELGIUM 


\section{PACIFIC JOURNAL OF MATHEMATICS EDITORS}

\author{
V. S. VARADARAJAN (Managing Editor) \\ University of California \\ Los Angeles, CA 90024 \\ Charles R. DePrima \\ California Institute of Technology \\ Pasadena, CA 91125 \\ R. FINN \\ Stanford University \\ Stanford, CA 94305
}

\author{
HeRmanN FlaschKa \\ University of Arizona \\ Tucson, AZ 857.21
}

RAMESH A. GANGOLli

University of Washington

Seattle, WA 98195

ROBION KIRBY

University of California

Berkeley, CA 94720
C. C. MOORE

University of California

Berkeley, CA 94720

H. SAMELSON

Stanford University

Stanford, CA 94305

HAROLD STARK

University of California, San Diego

La Jolla, CA 92093

\section{ASSOCIATE EDITORS}
R. ARENS
E. F. BECKENBACH
B. H. NeumanN
F. WOLF
K. YoSHIDA
(1906-1982)

\section{SUPPORTING INSTITUTIONS}

\begin{abstract}
UNIVERSITY OF ARIZONA
UNIVERSITY OF BRITISH COLUMBIA

CALIFORNIA INSTITUTE OF TECHNOLOGY

UNIVERSITY OF CALIFORNIA

MONTANA STATE UNIVERSITY

UNIVERSITY OF NEVADA, RENO

NEW MEXICO STATE UNIVERSITY

OREGON STATE UNIVERSITY
\end{abstract}

\author{
UNIVERSITY OF OREGON \\ UNIVERSITY OF SOUTHERN CALIFORNIA \\ STANFORD UNIVERSITY \\ UNIVERSITY OF HAWAII \\ UNIVERSITY OF TOKYO \\ UNIVERSITY OF UTAH \\ WASHINGTON STATE UNIVERSITY \\ UNIVERSITY OF WASHINGTON
}

The Supporting Institutions listed above contribute to the cost of publication of this Journal, but they are not owners or publishers and have no responsibility for its content or policies.

Mathematical papers intended for publication in the Pacific Journal of Mathematics should be in typed form or offset-reproduced (not dittoed), double spaced with large margins. Please do not use built up fractions in the text of the manuscript. However, you may use them in the displayed equations. Underline Greek letters in red, German in green, and script in blue. The first paragraph must be capable of being used separately as a synopsis of the entire paper. In particular it should contain no bibliographic references. Please propose a heading for the odd numbered pages of less than 35 characters. Manuscripts, in triplicate, may be sent to any one of the editors. Please classify according to the scheme of Math. Reviews, Index to Vol. 39. Supply name and address of author to whom proofs should be sent. All other communications should be addressed to the managing editor, or Elaine Barth, University of California, Los Angeles, California 90024.

There are page-charges associated with articles appearing in the Pacific Journal of Mathematics. These charges are expected to be paid by the author's University, Government Agency or Company. If the author or authors do not have access to such Institutional support these charges are waived. Single authors will receive 50 free reprints; joint authors will receive a total of 100 free reprints. Additional copies may be obtained at cost in multiples of 50 .

The Pacific Journal of Mathematics is issued monthly as of January 1966. Regular subscription rate: $\$ 190.00$ a year (5 Vols., 10 issues). Special rate: $\$ 66.00$ a year to individual members of supporting institutions.

Subscriptions, orders for numbers issued in the last three calendar years, and changes of address should be sent to Pacific Journal of Mathematics, P.O. Box 969, Carmel Valley, CA 93924, U.S.A. Old back numbers obtainable from Kraus Periodicals Co., Route 100, Millwood, NY 10546.

The Pacific Journal of Mathematics at P.O. Box 969, Carmel Valley, CA 93924 (ISSN 0030-8730) publishes 5 volumes per year. Application to mail at Second-class postage rates is pending at Carmel Valley, California, and additional mailing offices. Postmaster: Send address changes to Pacific Journal of Mathematics, P.O. Box 969, Carmel Valley, CA 93924.

PUBLISHED BY PACIFIC JOURNAL OF MATHEMATICS, A NON-PROFIT CORPORATION

Copyright $\odot 1985$ by Pacific Journal of Mathematics 


\section{Pacific Journal of Mathematics}

Vol. 120, No. $2 \quad$ October, 1985

Philip Marshall Anselone and Mike Treuden, Regular operator

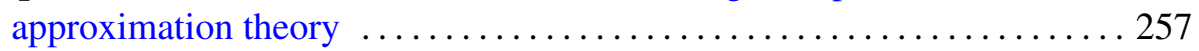

Giuseppe Baccella, Semiprime $\aleph-Q F 3$ rings $\ldots \ldots \ldots \ldots \ldots \ldots \ldots \ldots . \ldots \ldots$

Earl Robert Berkson and Thomas Alastair Gillespie, The generalized M.

Riesz theorem and transference $\ldots \ldots \ldots \ldots \ldots \ldots \ldots \ldots . \ldots 279$

Joachim Boidol, A Galois-correspondence for general locally compact

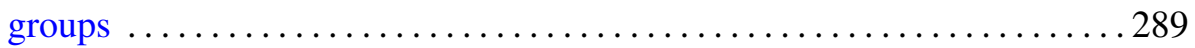

Joseph Eugene D'Atri, Josef Dorfmeister and Yan Da Zhao, The isotropy

representation for homogeneous Siegel domains ............... 295

C. Debiève, On Banach spaces having a Radon-Nikodým dual

Michael Aaron Freedman, Existence of strong solutions to singular

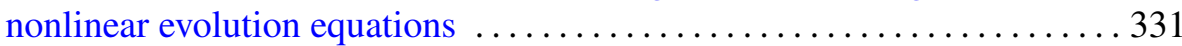

Francisco Jose Freniche, Grothendieck locally convex spaces of continuous

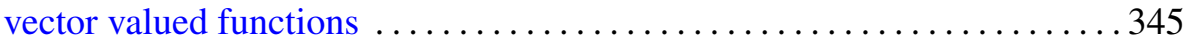

Hans-Peter Künzi and Peter Fletcher, Extension properties induced by complete quasi-uniformities . ............................ 357

Takaŝi Kusano, Charles Andrew Swanson and Hiroyuki Usami, Pairs of

positive solutions of quasilinear elliptic equations in exterior domains . . 385

Angel Rafael Larotonda and Ignacio Zalduendo, Spectral sets as Banach

manifolds

J. Martínez-Maurica and C. Pérez García, A new approach to the

Kreı̆n-Milman theorem

Christian Pommerenke, On the boundary continuity of conformal maps . . . 423

M. V. Subba Rao, Some Rogers-Ramanujan type partition theorems

Stephen Edwin Wilson, Bicontactual regular maps .........

Jaap C. S. P. van der Woude, Characterizations of (H)PI extensions

Kichoon Yang, Deformation of submanifolds of real projective space

Subhashis Nag, Errata: "On the holomorphy of maps from a complex to a

real manifold" 